\title{
Determining the Physical Properties of Aggregate Products and its Suitability for Road Base Construction, Ethiopia
}

\author{
Ashebir Alyew Mamo ${ }^{1}$ \\ ${ }^{1}$ Lecturer, \\ Civil Engineering Department, \\ Wolaita Sodo Univeristy, Ethiopia
}

\author{
Matusala Bassa Dagoye ${ }^{2}$ \\ ${ }^{2}$ Lecturer, \\ Civil Engineering Department, \\ Wolaita Sodo Univeristy, Ethiopia
}

\author{
Ashenafi Reta Tessema ${ }^{3}$ \\ ${ }^{3}$ Lecturer, \\ Civil Engineering Department, \\ Wolaita Sodo Univeristy, Ethiopia
}

\begin{abstract}
Normal aggregates are commonly mined from larger rock formations through an open quarry; the mined rock is reduced to usable proportions by crushing machine. From those materials in construction projects, the widely used one is a natural aggregate, which is a collective term for the mineral materials such as sand, gravel, and crushed stone that are used with a binding medium. Aggregates are one of the major components of highway material which is basically used in highway pavement layers such as base course. For the determination of the suitability of coarse aggregates as a road base construction material, conducting an appropriate physical test was essential. The study was carried out to determine some of the physical properties of natural aggregate products which are obtained around Arba Minch area. For naturally obtained basaltic parent rock, aggregate crushing plant in three different sites around Arba Minch were established, considering the availability of aggregate products of the study area and to approve its suitability, the physical tests of aggregate were conducted by the research team using Sieve test, Impact test, Aggregate Crushing Value test, Aggregate Abrasion Value test, Specific Gravity and Water Absorption test are the tests that have been carried out to evaluate the engineering properties of the natural rock aggregates. Laboratory test result concluded from the three quarry sites (Kulfo, Secha, and Mirab Abaya) showed that the natural aggregates manufactured in Arba Minch areas are good for road base construction because the test result satisfies the ERA, AASHTO, and ASTM specification requirements. Finally the research group concluded the study by providing essential recommendation for further study on the suitability of aggregate qualities for road base construction around the study area, so it will be better to conduct chemical tests of the aggregates because the site has many aggregate source so as to allocate the good product to other required areas.
\end{abstract}

Key Words: Aggregate, Moisture content, Sieve, Base-Course, Unit weight

\section{INTRODUCTION}

Aggregate is a collective term for the mineral materials such as sand, gravel, and crushed stone that are used with a binding medium (such as water, bitumen, Portland cement, lime, etc.) to form compound materials (such as bituminous concrete and Portland cement concrete). Ordinary construction aggregate is one of the most abundant natural resources and one of the most widely used. They are usually dug or dredged from a quarry, river, lake, or seabed. Construction aggregate is the sized, or crushed and sized, rock material used in concrete and asphalt, which make up most of highways, bridges, houses and other engineering works. Aggregates range in size from large boulders (rip rap) used as fill in large construction projects to finely-grained sized particles used in paint, glass, plastic, medicine, agricultural feed and soil conditioners, and many other industrial and household products. Construction aggregates are also used in water purification, emissions control, soil erosion control, and other environmental improvement products [1]. Hence aggregates must conform to certain standards for optimum engineering use: they must be clean, hard, strong, durable particles free of absorbed chemicals, coatings of clay, and other fine materials in amounts that could affect hydration and bond of the cement paste. Aggregate particles that are capable of being split are undesirable. Aggregates containing any appreciable amounts of shale or other shale rocks, soft and porous materials should be avoided, Normal weight aggregates should meet the requirements of ASTM C-33. There are several reasons for specifying both grading limits and maximum aggregate size [2]. More than $90 \%$ of asphalt pavement and $80 \%$ of concrete consist of construction aggregate. The remainder is a binder such as asphalt or cement. Aggregates are essential not only as a foundation for pavements, but also constitute the cement that makes the road itself. When a road is finished, the upper layers provide protection for the sub-base [1]. Aggregates are one of the major components of highway material which is basically used in highway pavement layers such as base course. Aggregates are known to be particles of rock or equivalent which, when brought together in a bound or unbound condition, form part or whole of an engineering or building structure. Aggregate is also used for base and sub-base courses for both flexible and rigid pavements. Aggregates 
can either be natural or manufactured. Natural aggregates are generally extracted from larger rock formations through an open excavation (quarry). Extracted rock is typically reduced to usable sizes by crushing plant. Manufactured aggregate is often a bye product of other manufacturing industries. Aggregates in pavement should be strong, hard and tough, not be flaky and elongate, durable, free from deleterious particles [3]. The study was carried out to determine some of the physical properties of natural aggregate products which are obtained around Arba Minch area and its suitability for use of civil engineering constructions, specifically for road base construction.

\section{LITERATURE REVIEW}

\subsection{Classifications of Aggregates}

Aggregates can be classified as natural or artificial depending on their sources. Natural aggregates are obtained from quarries by processing crushed rocks or from riverbeds while artificial aggregates are obtained from industrial by products such as blast furnace slag. Natural aggregates are most commonly obtained and are relevant for Ethiopian construction sector since artificial aggregates are hardly produced in the country [4]. Fundamentally three classes of aggregates are identified depending on their weight: light weight, normal weight and heavy weight. Lightweight aggregates are aggregates whose maximum dry loose bulk density is about $880 \mathrm{~kg} / \mathrm{m}^{3}$ for course aggregates and $1040 \mathrm{Kg} / \mathrm{m}^{3}$ for all-in aggregates. Lightweight aggregates are classified as natural and artificial depending on how they are secured. The main natural lightweight aggregates are diatomite, pumice, scoria, volcanic cinder, and tuff. Except for diatomite, all are volcanic in origin. Pumice and scoria are more widely used for hollow and solid concrete block production in Ethiopia. Normal weight aggregate is generally produced in Ethiopia by crushing parent rocks using mechanical crushers or traditional methods. Basaltic rock is a good example of parent rock, which is used mainly for coarse aggregate production in and around [4].

2.2. Properties of Aggregate

The physical properties which are specific gravity, porosity, thermal behavior, and the chemical properties of an aggregate are attributed to the parent material [4]. Good quality of natural course aggregates should be product of gravel of broken stones and should be chemically inert, hard, strong, and clean, they should not be highly water absorbent, and have to be non-porous, they should be roughly cubical shape with rough surface, flaky and elongated aggregates should not be used, they should also be free from other fine materials. Some of the factors most commonly recognized as affecting unbound aggregate layer behavior include particle shape and surface texture, type and amount of fines, achieved in-place density, and moisture content in relation to the required compaction level. Quantifying the relative effects of the aggregate physical properties on performance would significantly improve safe, efficient, and sustainable designs of unsurfaced pavement systems [5]. Aggregate Impact test, Aggregate Crushing Value test, Aggregate Abrasion Value test, Specific Gravity and Water Absorption, Flakiness Index, Slake Durability Test, The Stripping Test (Bitumen Adhesion test) are the tests that have been carried out to evaluate the engineering properties of the rock aggregates [6]. The study results of [5] showed that aggregate properties had varying levels of influence on the modulus and permanent deformation characteristics of unbound aggregates; hence protecting the subgrade may not be the only consideration when designing rut-resistant unsurfaced pavement systems, and due consideration should be given to aggregate type and quality and their effects on both modulus and permanent deformation behavior of the pavement layers.

The above researchers in their study determined that the physical properties of aggregates have greater influence on the supporting structure of pavement layers, due to poor behavior of aggregate materials; its suitability for road base construction will be affected. Hence proper physical properties of aggregates which were manufactured around Arba Minch from different quarry sites were carefully determined to check its suitability for the said purposes consequently.

\subsection{Materials}

\section{MATERIALS AND METHODS}

To study the physical properties of aggregate products and its suitability for road base construction: sieve, crushed aggregate, balance, oven, dish, water, Ponding surface, impact testing machine, compression testing machine, abrasion machine, brushes, and sample container are used and the physical properties of the aggregate products are stated as below.

\subsection{Methods}

Aggregate tests are necessary to determine the suitability of the material for a specific use and to make sure that the required properties are consistently within specification parameters. The sections under provides experimental test outcomes for aggregates of Arba Minch produced from selected quarry sites like ( Kulfo, Secha and Mirab Abaya) aggregate production plant sites. For the determination of tests and test results, AASHTO, ERA, ASTM, Standards for aggregate tests are seen in comparison [7].

\subsection{Aggregate tests}

Aggregate tests are necessary to determine the suitability of the material for a specific use and to make sure that the required properties are consistently within specification limits. The following physical tests of aggregates are determined using different tests for evaluating the suitability of coarse aggregates for road base construction from Arba Minch area of different quarry sites.

4.1.1. Grading test for coarse aggregate:

A sieve test is used to determine particle size distribution of stone aggregates. Different sizes of aggregate in proper proportion will result in dense and durable road base course. Aggregates containing particles of different sizes in suitable proportion is known as well-graded aggregate. Grading test also termed as sieve analysis, screen analysis or mechanical analysis, it is the most common test performed on aggregates to evaluate their grain size distribution for a specific use. Gradation is determined by separating the aggregates into 
portions, which are retained on a number of sieves or screens having specified openings, which are suitably graded from course to fine. The results obtained may be expressed either as total percentage passing or retained on each sieve or as the percentages retained between successive sieves. The following table shows Grading Limits for graded crushed stone of base Coarse Materials (GB1) of ERA manual and the observed value of Arba Minch area quarry sites.

Table 1: Laboratory test result of Gradation test

\begin{tabular}{|c|c|c|c|c|c|c|c|}
\hline Sieve size & Sieve weight & $\begin{array}{c}\text { Total } \\
\text { weight }\end{array}$ & $\begin{array}{l}\text { Retained aggr. } \\
\text { Weight }\end{array}$ & $\begin{array}{c}\text { Retained weight } \\
\text { by } \%\end{array}$ & $\begin{array}{l}\text { Cumulative } \\
\text { retained } \%\end{array}$ & $\%$ passing & $\begin{array}{c}\text { ERA manual }(A A S H T O \\
T 27 \& T 11)\end{array}$ \\
\hline 50 & 489.2 & 489.2 & 0 & 0 & $0 \%$ & $100 \%$ & \\
\hline 19 & 690.2 & 1302.7 & 612.5 & $19.8 \%$ & $23.5 \%$ & $76.5 \%$ & $60-80$ \\
\hline 9.5 & 735.6 & 1522.7 & 787.1 & $25.4 \%$ & $48.9 \%$ & $51.1 \%$ & $40-60$ \\
\hline 4.75 & 615.1 & 1410.4 & 795.3 & $25.7 \%$ & $74.6 \%$ & $25.4 \%$ & $25-40$ \\
\hline Pan & 269.5 & 1055.6 & 786.1 & $25.4 \%$ & $100.0 \%$ & $0.0 \%$ & 0 \\
\hline
\end{tabular}



Figure 1: Sieve test value for coarse aggregate

Retained Weight by $\%=\frac{\text { Retained aggr.Weight }}{\text { Cumulative agg.weight }} * 100$

Discussions: In road construction while working with HMA Concrete is primarily used on the surface of pavements, there are several underlying layers that play a critical role in the performance of a pavement. This includes bases, subbases, and subgrades. The laboratory result of the sieve analysis for base course test satisfy the [7] and [8] requirement and thus it is well graded aggregate material as the laboratory gradation test above indicates. AASHTO and ERA tests are currently available to test these materials to determine if they are suitable for use under Pavement layers especially for road base coarse construction [7].

\subsubsection{Specific gravity of coarse aggregate}

The central objective of specific gravity test is to measure the strength or quality of the material and to determine the water absorption of aggregates. Four moisture conditions are defined for aggregates depending on the amount of water held in the pores or on the surface of the particles.

$\checkmark$ Damp or wet Aggregate in which the pores connected to the surface are filled with water and with free water also on the surface. $\checkmark \quad$ Saturated surface-dry Aggregate in which the pores connected to the surface are filled with water but with no free water on the surface.

$\checkmark$ Air-dry Aggregate that has a dry surface but contains some water in the pores.

$\checkmark$ Oven-dry Aggregate that contains no water in the pores or on the surface.

The volume of the aggregate particle is usually assumed to be the volume of solid matter and internal pores. Different values of specific gravity may be calculated depending on whether the mass used is an oven-dry or a saturated surface dry mass. Bulk specific gravity is the oven-dry mass divided by the mass of a volume of water equal to the SSD aggregate volume; while SSD bulk specific gravity is the saturated surface-dry mass divided by the mass of a volume of water equal to the SSD aggregate volume. Most normal weight aggregates have a bulk specific gravity SSD between 2.5 and 3.0. Different types of specific gravity are commonly used depending upon how the volume of water permeable voids (or pores) within the aggregate are addressed.

$\checkmark$ Apparent Specific Gravity, $\mathrm{G}_{\mathrm{sa}}$

$\checkmark$ Bulk Specific Gravity (Bulk Dry Specific Gravity), $\mathrm{G}_{\mathrm{sb}}$

$\checkmark$ Bulk Saturated Surface Dry (SSD) Specific Gravity. 
Calculations

$$
\begin{aligned}
& \text { Bulk specific gravity }=\frac{A}{B-C} \\
& \text { Bulk SSD specific gravity }=\frac{B}{B-C} \\
& \text { Apparent specific gravity }=\frac{A}{A-C}
\end{aligned}
$$

Where:

$$
\begin{aligned}
& \mathrm{A}=\text { mass of oven-dry sample in air }(\mathrm{g}) \\
& \mathrm{B}=\text { mass of SSD sample in air }(\mathrm{g}) \\
& \mathrm{C}=\text { mass of SSD sample in water }(\mathrm{g})
\end{aligned}
$$

\subsubsection{Absorption of coarse aggregate}

Absorption is a measure of the amount of water that an aggregate can absorb into its pore structure. Pores that absorb water are also referred to as "water permeable voids". Absorption can be used as an indicator of aggregate durability as well as the volume of asphalt binder it is likely to absorb.

\section{Aggregate Absorption Use}

Aggregate absorption is the increase in mass due to water in the pores of the material. Aggregate absorption is a useful quality because: High values can indicate non-durable aggregate and high absorption can indicate the amount of asphalt binder the aggregate will absorb.

\section{Calculation}

Absorption $($ in percent $)=\left(\frac{B-A}{A}\right) * 100$

Where:

$\mathrm{A}=$ mass of oven-dry sample in air $(\mathrm{g})$

\begin{tabular}{|c|c|c|c|c|c|}
\hline \multirow[t]{2}{*}{ Items } & \multirow{2}{*}{\multicolumn{2}{|c|}{ Description }} & \multicolumn{3}{|c|}{ SAMPLE NO } \\
\hline & & & $\mathbf{I}$ & II & III \\
\hline A & \multicolumn{2}{|c|}{ Weight saturated surface dry sample in air (B), $g$} & 1488.5 & 1527.5 & 1491.6 \\
\hline $\mathrm{B}$ & \multicolumn{2}{|c|}{ Weight wire mesh in water, $\mathrm{g}$} & 670 & 670 & 670 \\
\hline $\mathrm{D}$ & \multicolumn{2}{|c|}{ Weight of sample in water (C), g } & 956.1 & 995 & 976.5 \\
\hline $\mathrm{E}$ & \multicolumn{2}{|c|}{ Weight of oven dry sample (A), g } & 1477.5 & 1521.3 & 1486.3 \\
\hline $\mathrm{F}$ & \multicolumn{2}{|c|}{ Bulk specific gravity $=\mathrm{A} /(\mathrm{B}-\mathrm{C})$} & 2.77 & 2.85 & 2.89 \\
\hline $\mathrm{G}$ & \multicolumn{2}{|c|}{ Bulk SSD specific gravity=B/(B-C) } & 2.79 & 2.86 & 2.90 \\
\hline $\mathrm{H}$ & \multicolumn{2}{|c|}{ Apparent specific gravity= A/(A-C) } & 2.83 & 2.89 & 2.92 \\
\hline $\mathrm{I}$ & \multicolumn{2}{|c|}{ Water absorption (\%) } & 0.74 & 0.40 & 0.36 \\
\hline \multirow{4}{*}{\multicolumn{2}{|c|}{ Average value of the three sites }} & Bulk specific gravity & \multicolumn{3}{|l|}{2.84} \\
\hline & & Bulk SSD specific gravity & \multicolumn{3}{|l|}{2.85} \\
\hline & & Apparent specific gravity & \multicolumn{3}{|l|}{2.64} \\
\hline & & Water absorption & \multicolumn{3}{|l|}{0.50} \\
\hline
\end{tabular}

$\mathrm{B}=$ mass of SSD sample in air $(\mathrm{g})$

$\mathrm{C}=$ mass of SSD sample in water $(\mathrm{g})$

Determination of specific gravity and water absorption, for aggregate greater than $4.74 \mathrm{~mm}$ sieve

Table 2: Specific gravity and water absorption observation sheet

Discussions: The specific gravity of aggregates normally used in road construction ranges from about 2.5 to 3.0 with an average of about 2.68. Though high specific gravity is considered as an indication of high strength, it is not possible to judge the suitability of a sample road aggregate without finding the mechanical properties such as aggregate crushing, impact and abrasion values. Water absorption shall not be more than $\mathbf{0 . 6}$ per unit by weight. Hence in case of Arba Minch area the aggregate products were experimentally observed with a lower level of water absorption with a value of $0.50 \%$, indicating it's appropriateness for road base construction works.

2.4. Moisture Content of coarse Aggregate

The test is done according to [7] T-85, and the objective of this test is to determine the moisture content of coarse aggregate. Basically there are different Moisture States, since aggregates contain some porosity, water can be absorbed into the body of the particles or retained on the surface of the particle as a film of moisture. The four moisture states are defined:

- Oven-dry (OD): All moisture is removed from the aggregate by heating in an oven at $105^{\circ} \mathrm{C}$ to constant weight (overnight heating usually is sufficient). All pores are empty.

- Air-dry (AD): All moisture removed from surface, but internal pores partially full.
- Saturated-surface-dry (SSD): All pores filled with water, but no film of water on the surface.

- Wet: All pores completely filled with water with a film on the surface.

Of these four states, only OD and SSD states correspond to specific moisture contents, and either of these states can be used as reference states for calculating moisture contents. Conducting all the required steps the following result were drawn.

Observed Results:

Moisture content of coarse aggregate (w) in \% = $\frac{\mathrm{W} 1-\mathrm{W} 2}{\mathrm{~W} 2} * 100$

Weight of original sample $(\mathrm{W} 1)=304.2$ gram

Weight of oven dry sample $(\mathrm{W} 2)=302.0$ gram

Calculation:

$\mathrm{w}(\%)=\frac{\mathrm{W} 1-\mathrm{W} 2}{\mathrm{~W} 2} * 100=\frac{(304.2-302.0)}{302.0} * 100=0.73 \%$

Where: $\mathrm{w}-$ moisture content in percent

W1 - Weight of original sample

W2 - Weight of oven dry sample

Discussions: The result obtained from the lab test conducted was $\mathbf{0 . 7 3 \%}$ shows the moisture content of the aggregate. High moisture content indicates high porosity of aggregates, which have potentially durability problem. But in case of Arba Minch sites aggregate which were sampled from three potential areas (Kulfo, Secha and Mirab Abaya aggregate production sites) the moisture content of the aggregate were 
very less and it indicates the minimum porosity, high strength and potential durability of the aggregate production in the sites.

\subsection{Unit weight of aggregate}

Unit weight is the unit of a given volume of graded aggregate. It is thus a density measurement and is also known as bulk density. The degree of compaction the road base material will change the amount of void space, and hence the value of unit weight. Weight of aggregate is dependent on moisture content of aggregate, a constant moisture content is required [9]. For this test moisture content obtained was $0.73 \%$. The compacted and lose weight of aggregate determination was conducted in the lab and the result is as follow.

Table 3: Test result of compacted weight of coarse aggregate

\begin{tabular}{|c|c|c|c|c|}
\hline S.No & Weight of cylinder $(\mathbf{k g})$ & Total weight $(\mathbf{c y}+\mathbf{a g g}) \mathbf{k g}$ & Net wt agg. (kg) & Volume of cylinder \\
\hline 1 & 8.35 & 30.25 & 21.90 & $0.01 \mathrm{~m}^{3}$ \\
\hline 2 & 8.35 & 31.81 & 23.46 \\
\hline 3 & 8.35 & 31.00 & 22.65 \\
\hline
\end{tabular}

Bulk density $=\frac{\text { Average net weight of aggregate }}{\text { volume of cylinder }} \ldots . .(7)$

Average Bulk density of the aggregate $=\frac{22.67 \mathrm{~kg}}{0.01 \mathrm{~m}^{3}}$

$$
=2267 \frac{\mathrm{kg}}{\mathrm{m}^{3}}
$$

Discussions: the aggregate products of the Arba Minch quarry sites are manufactured from the basaltic stone with a category of heavy weight aggregate. Hence the computed result of aggregate products of the study area revealed an incredible result, which satisfies the minimum requirement set by [7] under ASTM C-337.

Table 4: Test result of lose weight of coarse aggregate

\begin{tabular}{|l|c|c|c|c|}
\hline S.No & Weight of cylinder(kg) & Total weight $(\mathrm{cy}+\mathrm{agg}) \mathrm{kg}$ & Net wt. agg. (kg) & 21.4 \\
\hline 1 & 8.35 & 29.75 & $0.01 \mathrm{~m}^{3}$ \\
\hline 2 & 8.35 & 30.35 & 22.0 \\
\hline 3 & 8.35 & 29.75 & 21.4 \\
\hline
\end{tabular}

Bulk density $=\frac{\text { Average net weight of aggregate }}{\text { volume of cylinder }}$

Bulk density $=\frac{\text { Average net weight of aggregate }}{\text { volume of cylinder }}=\frac{21.6}{0.01} \frac{\mathrm{kg}}{\mathrm{m}^{3}}=$ $2160 \frac{\mathrm{kg}}{\mathrm{m}^{3}}$

Discussions: the measured lose weight of coarse aggregate products of the Arba Minch quarry sites are manufactured from the basaltic stone with a category of heavy weight aggregate. Hence the computed result also satisfies the minimum requirement set by [7] under ASTM C-337.

\subsection{Aggregate Crushing value test}

Aggregate crushing test evaluates the resistance of aggregates against the gradually applied load. The test is used to evaluate the crushing strength of available supplies of rock in construction, to make sure that minimum specified values are maintained. The test is undertaken using a metal plunger to apply gradually a standard load of $400 \mathrm{kN}$ to a sample of the aggregate $(10-14 \mathrm{~mm})$ contained in a standard test mold. The amount of material passing $2.36 \mathrm{~mm}$ sieve in percentage of the total weight of the sample is referred to as the Aggregate Crushing value (ACV). Over the range of normal road making aggregates, ACVs vary from 5 percent for hard aggregates to 30 percent for weaker aggregates [7].

Table 5: Test result of aggregate crushing value

\begin{tabular}{|l|c|c|c|c|}
\hline \multicolumn{1}{|c|}{ Items } & Equation/Symbol & Sample 1 & Sample 2 & Sample 3 \\
\hline Total weight of dry sample taken & $\mathrm{W} 1$ & 3463.3 & 3723.8 & 3502.6 \\
\hline Weight of portion passing 2.36mm sieve & $\mathrm{W} 2$ & 298.2 & 316.3 & 320.4 \\
\hline Aggregate crushing value & $\mathrm{ACV}=(\mathrm{W} 2 / \mathrm{W} 1)^{*} 100$ & 8.610 & 8.494 & 9.147 \\
\hline & $\begin{array}{c}\text { Average aggregate } \\
\text { crushing value (ACV) }\end{array}$ & $\mathbf{8 . 7 5 \%}$ & \\
\hline
\end{tabular}

Discussions: Aggregate crushing value of 30 percent and above is not good for road construction, hence in case of Arba Minch natural aggregate the determined ACV was $\mathbf{8 . 7 5 \%}$ which is too less than $30 \%$ indicating the good resistance of aggregate to the applied load.

\subsection{Aggregate Impact value test}

This test is a means of evaluating the resistance of aggregates to sudden impact loading. It is carried out by filling a steel test mold with a sample of aggregate (10 - 14 $\mathrm{mm}$ ) and then the impact load applied is by dropping hammer at a height of $380 \mathrm{~mm}$. The Aggregate Impact Value (AIV) is the percentage of fines passing $2.36 \mathrm{~mm}$ BS test sieve after 15 blows [9]. 
Table 6: Test result of aggregate impact value

\begin{tabular}{|l|c|c|c|c|}
\hline \multicolumn{1}{|c|}{ Items } & Equation/Symbol & Sample 1 & Sample 2 & Sample 3 \\
\hline Total weight of dry sample taken & W1 & 359.6 & 346.4 & 362.9 \\
\hline Weight of portion passing 2.36mm sieve & W2 & 36.8 & 33.2 & 38.48 \\
\hline Aggregate impact value & $=($ W2/W1)*100 & 10.23 & 9.58 & 10.60 \\
\hline \multicolumn{2}{|l|}{} & Average (AIV) & $\mathbf{1 0 . 1 4 \%}$ & \\
\hline
\end{tabular}

The aggregate impact value $=10.14 \%$

Discussions: the aggregate impact value gives a relative measure of the resistance of an aggregate to sudden impact, which in some aggregates differs from its resistance to slowly applied compressive load. Aggregate with aggregate impact value higher than $30 \%$ may be abnormal. But in case of the study area from three separate sites the aggregate impact value resulted too less than $30 \%$, which is also evaluated as a good aggregate for road base course construction.

\subsection{Abrasion Test}

Abrasion test is the test used to know how the aggregate is sufficiently hard to resist the abrasive effect of traffic over its service life. The most widely used abrasion test is the Los Angeles Abrasion test which involves the use of a steel drum, revolving on horizontal axis, into which the test sample of chippings is loaded together with steel balls of $46.8 \mathrm{~mm}$ diameter. The Los Angeles Abrasion Value (LAV) is the percentage of fines passing the $1.18 \mathrm{~mm}$ sieve after a 500 number of revolutions of the drum at specified speed. The drum is fitted with internal baffles causing the aggregate and the steel balls to be lifted and then fall as the drum revolves.
The test therefore gives an indication of the impact strength in combination with the abrasion resistance of the aggregate. Los Angel's Abrasion value specified in [7] T-96 is 50\%, which is much higher than the mean value obtained from the sample test results indicating that the basaltic stone of Arba Minch quarry sites is satisfactory in hardiness. Provided, the necessary gradation and physical identification were made, it should be possible to use the aggregate as road base course material produce higher strength quality. Grade B abrasion test has been conducted in lab by taking $2500 \mathrm{gm}$ of aggregate retained on $12.5 \mathrm{~mm}$ and $9.5 \mathrm{~mm}$ sieve.

Weight of aggregate retained on $19 \mathrm{~mm}$ sieve + Weight of aggregate retained on $9.5 \mathrm{~mm}$ sieve $(\mathrm{A}=1400 \mathrm{gm})$

Then, fine weight obtained (material) coarser than $1.18 \mathrm{~mm}$ sieve $(\mathrm{B}=786.1)$

$$
\begin{array}{r}
\text { Percentage of wear }=\left(\frac{A-B}{B}\right) * 100 \quad \ldots \ldots \ldots \\
\% \text { of wear }=\left(\frac{1400-786}{1400}\right) * 100=\mathbf{4 3} \%
\end{array}
$$

The Los Angeles Abrasion value, determined by testing in accordance with AASHTO T-96 shall not exceed 45 at 500 revolutions.

Discussions: the obtained percentage of wear (\%) was below the [7] T-96 standard, indicating the blameless quality of aggregate for road base construction.

Table 7: Summary physical properties of coarse aggregates

\begin{tabular}{|c|l|c|}
\hline Tests & \multicolumn{1}{|c|}{ Physical Properties of Arba Minch area natural aggregate } & Units \\
\hline & Absorption & $0.5 \%$ \\
\hline 2 & Moisture Content & $0.73 \%$ \\
\hline 3 & Bulk Specific Gravity of Coarse Aggregate & 2.84 \\
\hline 4 & Bulk Specific Gravity of Coarse Aggregate(SSD Basis) & 2.85 \\
\hline 5 & Apparent Specific Gravity of Coarse Aggregate & $8.75 \%$ \\
\hline 6 & Average Aggregate Crushing Value (ACV) & $10.14 \%$ \\
\hline 7 & Aggregate Impact Value (AIV) & $43 \%$ \\
\hline 8 & The Los Angeles Abrasion value & $2260 \frac{\mathrm{kg}}{\mathrm{m}^{3}}$ \\
\hline 9 & Compacted weight of coarse aggregate & $2160 \frac{\mathrm{kg}}{\mathrm{m}^{3}}$ \\
\hline 10 & Lose weight of coarse aggregate & \multirow{2}{*}{} \\
\hline
\end{tabular}

\section{CONCLUSIONS}

From above discussions of laboratory result it was concluded that the Kulfo, Secha, and Mirab Abaya quarry site aggregates are good for road base construction because the test result satisfies the ERA, AASHTO and ASTM requirements or specifications. According to the laboratory result of three quarry sites sieve analysis, abrasion, aggregate crushing value, Aggregate Impact value, Absorption, moisture content and other tests are very good for road base course material. For further approval and suitability of aggregate qualities for road base construction around the study area, it is better to conduct chemical tests of the aggregates because the site has many aggregate source so as to allocate the good product to other required areas. 


\section{REFERENCES}

[1] Ndukauba Egesi and Akaha C. Tse, "Engineering-Geological Evaluation of Rock Materials from Bansara, Bamenda Massif Southeastern Nigeria, as Aggregates for Pavement Construction," in Scientific \& Academic Publishing, Nijeria, 2012.

[2] Shafak Noori H. Barzargi, Assist. Prof.Dr. Hamed M.Jassim, Sarmad Fadhil Abdullah and Shukri Saleh Mohamed, "A Comparative Study of the Suitability of Dakuk, Kirkuk-Iraq and Tuz, Salahaddin-Iraq Coarse Aggregates for Construction Purposes," International Journal of Engineering Trends and Technology (IJETT), vol. Volume 10, 2014.

[3] Mathew, Prof. Tom V., "https://www.civil.iitb.ac.in," 24092010 [Online]. [Accessed 2911 2019].

[4] Abebe Dinku, "The Need for Standardization of Aggregates for Concrete Production in Ethiopian Construction Industry," in Addis Ababa University, Ethiopia, Addis Abeba, 2005.

[5] Debakanta Mishra, Ph.D., A.M.ASCE and Erol Tutumlner PhD., A. M.S.CE, "Aggregate Physical Properties Affecting Modulus and Deformation Characteristics of Unsurfaced Pavements," Journal of Materials in Civil Engineering, vol. 24, no. 9, pp. 1144 - 1152, 2012.

[6] Indira Baruah Gogoi, Dr. Diganta Goswami and Girindra Deka, "A Study of River-Borne Aggregates of River Nanoi as Construction Material," SSRG International Journal of Civil Engineering (SSRGIJCE), vol. 2, no. 5, 2015.

[7] Officials American Association of State Highway and Transportation, "Standard Specifications for Transportation Materials and Methods of Sampling and Testing," 26 ed., American Association of State Highway and Transportation Officials, 2006.

[8] Ethiopian Road Authority, Standard Technical Specifications, Addis Ababa: FEDERAL DEMOCRATIC REPUBLIC OF ETHIOPIA, 2002.

[9] Abebe Dinku, Construction Materials Laboratory Manual, Addis Ababa: Addis Ababa University Printing Press, 2002. 